\title{
Single Pile Settlement and Load Transfer Mechanism due to Excavation in Silty Clay
}

\author{
Mukhtiar Ali Soomro \\ Department of Civil Engineering \\ Quaid-e-Awam University of \\ Engineering, \\ Science \& Technology \\ Nawabshah, Pakistan \\ eng.soomro@gmail.com
}

\author{
Kiran Fatima Memon \\ Department of Civil Engineering \\ Quaid-e-Awam University of \\ Engineering, \\ Science \& Technology \\ Nawabshah, Pakistan \\ kiranf893@gmail.com
}

\author{
Mohsin Ali Soomro \\ Department of Civil Engineering \\ Quaid-e-Awam University of \\ Engineering, \\ Science \& Technology \\ Nawabshah, Pakistan \\ drmohsin@quest.edu.pk
}

\author{
Asad Memon \\ Department of Civil Engineering \\ Quaid-e-Awam University of Engineering, \\ Science \& Technology \\ Nawabshah, Pakistan \\ asadmemon10@hotmail.com
}

\author{
Manthar Ali Keerio \\ Department of Civil Engineering \\ Quaid-e-Awam University Engineering, \\ Science \& Technology \\ Larkana, Pakistan \\ mantharali99@quest.edu.pk
}

\begin{abstract}
In densely built areas, development of underground transportation system often involves excavations for basement construction and cut-and-cover tunnels which are sometimes inevitable to be constructed adjacent to existing piled foundations. In order to gain new insights into single pile responses (i.e. settlement and load transfer mechanism) to an adjacent excavation in saturated silty clay, a three-dimensional coupled- consolidation numerical analysis is conducted in this study. An advanced hypoplasticity (clay) constitutive model with small-strain stiffness was adopted. A linear increase in pile settlement was observed due to excavation-induced stress release. This is because part of the pile is placed within the boundaries of a major influence zone due to excavation-induced ground movement. Based on a settlement criterion, apparent loss of pile's capacity is $14 \%$. A maximum bending moment of about $350 \mathrm{kNm}$ is induced in the pile with the maximum deflection of $28 \mathrm{~mm}$. In addition, mobilisation of shear strength at the pile-soil interface was found to be a key factor governing pile-soil-excavation interaction. During excavation, a downward load-transfer mechanism in the piles can be identified.
\end{abstract}

Keywords-excavation; pile; silty clay; numerical modelling

\section{INTRODUCTION}

The development of underground space induces ground movements and stress release in the surrounding soil that may affect existing structures. Owing to the inherent lack of surface space in congested urban areas, deep excavation for basements and cut-and-cover tunnels are inevitably constructed adjacent to existing pile foundations often supporting high-rise buildings [1-2]. Thus, it is important for designers to estimate potential damage to existing piles resulting from nearby deep excavations. Most of the earlier researchers estimated the buildings settlement and tilting considering wall movements and ground surface settlement trough using empirical approaches. The performance of pile group depends on the stress state in the soil and surrounding sub-surface soil movements [3]. In addition, deep excavation in soft clay induces negative excess pore water pressure [4] which induces long term pile group settlement with the dissipation of excess pore water pressure. Therefore, it is essential to investigate the pile group response mechanism adjacent to deep excavation in soft soil. Authors in $[1,2]$ reported case studies in granular soil and alluvium residual soil respectively. They demonstrated that lateral soil movements due to excavation can be detrimental to nearby existing piles. In both reported case studies, pile toe level was much deeper than the excavation level and they reported only the lateral pile behavior. Apart from field monitoring, a number of centrifuge tests were also conducted to investigate the response of single pile [5] and pile group in soft kaolin clay [6]. They concluded that the induced bending moment and lateral pile deflection were highly influenced by the distance from the wall and pile head condition. In studies, lateral response of end bearing piles without initial applied load was reported. In reality, pile group in soft clay behave as floating pile group and subjected to initial applied load from superstructure. In the presence of initial applied load, soil surrounding the pile group experiences higher stress level before the commencement of adjacent excavation. Authors in [7-8] conducted centrifuge tests to investigate the effects of an unpropped excavation on the behaviours of nearby single piles and pile groups in dry dense Toyoura sand. It was found that the distance from the pile to the retaining wall and pile head 
conditions had a large influence on the induced pile bending moment and lateral deflection. Authors in [9] reported the results of three centrifuge tests which were carried out to study the effects of a multipropped deep excavation in-flight on the behaviour of single piles in dry Toyoura sand. Piles were laterally restrained in terms of rotation and deflection right at or above ground surface in the three different tests. It was concluded that lateral restraints imposed on the pile head have a significant influence on induced pile bending moment. Induced bending moment due to excavation can exceed the pile bending capacity. Authors in [10] developed design charts to compute the lateral behaviour of a single pile adjacent to deep excavation in soft ground. They performed two staged analysis considering plane strain conditions and linear elastic soil model. Similar work was conducted in [11] in which authors used finite element method. In both these studies lateral response of single pile was investigated. The settlement behavior of pile and development of excess pore water pressure and consolidation settlement were not investigated. Authors in [12] proposed an analytical method to investigate reduction of capacity and increase in settlement of nearby pile during excavation. It was reported that pile settlement due to excavation depends on the percentages of end bearing and shaft friction of the pile, the soil movement pattern, and the distribution of the maximum shaft friction with depth. However, shaft resistance in these methods is calculated on the assumption that horizontal stress acting on the piles does not change during excavation. This assumption may not be valid and the pile settlement may be underestimated using the preceding methods, leading to a non-conservative prediction. Most of the previous studies focused on the lateral response of single pile foundation. The vertical response of floating pile group combined with working load adjacent to deep excavation in soft clay has not been studied. Moreover, in soft clay progressive change in excess pore water pressure with time and consolidation settlement of pile group were not investigated.

It is well recognised that the stress-strain relationship of soils is highly nonlinear even at very small strain. The stiffness of most soils decreases as strain increases and depends on the recent stress or strain history of the soil [13-14]. Owing to nonlinear soil behaviour, an excavation can cause reduction to the ground stiffness. Therefore, it is vital to investigate the pile responses to adjacent excavation in silty clay. To obtain a satisfactory numerical model of the single pile responses to excavation-induced stress relief, the analysis must take account of the small strain non-linearity of soil. In view of the aforementioned issues, this study aims at investigating the settlement and load transfer mechanism of an existing single pile due to an adjacent excavation in saturated silty clay. To achieve these objectives, a three-dimensional coupledconsolidation numerical modelling was carried out. Settlement, axial load distribution along the pile, stress changes and excessive pore pressure generation during excavation are reported and discussed.

\section{THREE-DIMENSIONAL COUPLED CONSOLIDATION ANALYSIS}

To gain new insights into single pile responses to a nearby multipropped excavation in saturated silty clay, this study conducts a three-dimensional coupled consolidation numerical analysis. Figure 1(a) shows the elevation view of the configuration of numerical simulation in which a multipropped excavation was carried out adjacent to a single pile. The final depth of the excavation (He) was $10 \mathrm{~m}$. The embedded length $\left(\mathrm{L}_{\mathrm{p}}\right)$ and diameter $\left(\mathrm{d}_{\mathrm{p}}\right)$ of the pile were $18 \mathrm{~m}$ and $0.8 \mathrm{~m}$, respectively. The modelled pile represents a cylindrical reinforced concrete (grade 40 , reinforcement ratio $=1$ ) with a bending moment capacity of $800 \mathrm{kNm}$. The clear distance between diaphragm wall and the pile was $3.0 \mathrm{~m}(0.3 \mathrm{He})$. The excavation was supported by $0.6 \mathrm{~m}$ thick diaphragm wall. The ratio of wall penetration depth to excavation depth is typically $0.5-2$ in engineering practice [15-16], and thus a value of 0.5 was adopted in this study. The retaining wall was supported by three levels of props, at 1.0, 4.0 and $7.0 \mathrm{~m}$ depth. The props were modelled as soft with axial rigidity of $81 \times 10^{3} \mathrm{kNm}$ [15]. Horizontal spacing of props was $10 \mathrm{~m}$.

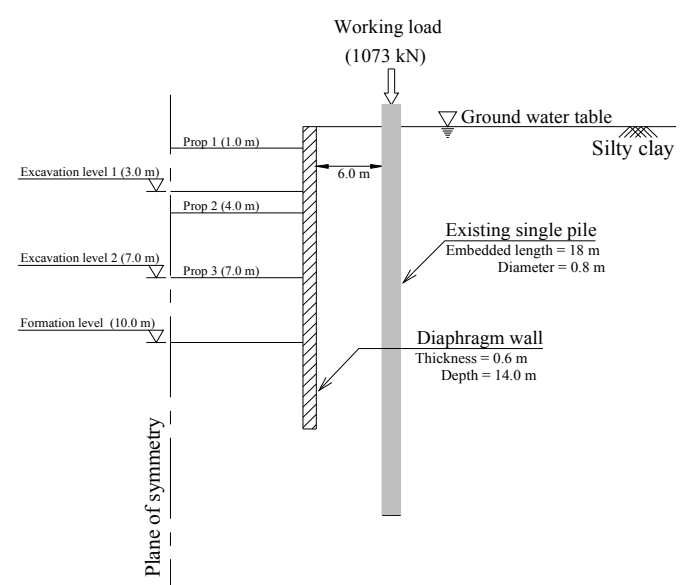

(a)

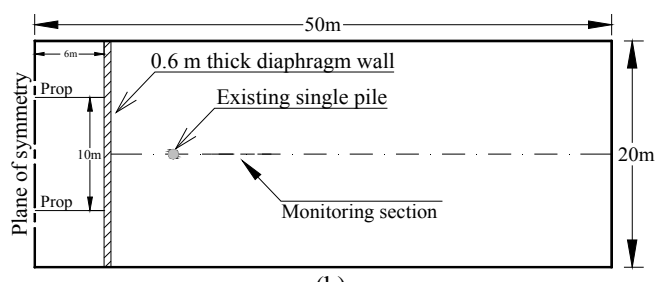

(b)

Fig. 1. Configuration of the numerical run (a) elevation, (b) plan view

It is worth noting that, in reality, high-rise buildings are unlikely to be built on a single pile. This hypothesised study is a virtual case [3, 17-18]. This simplification is made to understand the settlement and load transfer mechanism clearly. Figure 1(b) illustrates the plan view of the configuration of the numerical simulation. The length of the excavation is $12 \mathrm{~m}$. Due to symmetry, only half of the excavation was simulated. A monitoring section was selected at the transverse centreline of the excavation. In addition to this simulation, a pile load test (L) was conducted numerically in "greenfield" conditions (i.e., without excavation) to obtain the ultimate capacity of the pile in silty clay. Based on this, the working load was then calculated with a factor of safety of 3.0. The obtained working load was applied to the pile in the analysis simulating excavation. 


\section{A. Finite Element Mesh and Boundary Conditions}

Figure 2 shows an isometric view of a finite element mesh used to analyze the soil-pile-excavation problem. The size of the mesh for each numerical runs is $50 \mathrm{~m} \times 20 \mathrm{~m} \times 40 \mathrm{~m}$. These dimensions were sufficiently large to minimize boundary effects in the numerical simulation as further increment of the dimensions of the finite element mesh did not lead to any change in the computed results. Regarding the element size in the mesh, it is found that further halving of the adopted mesh size only leads to a change of computed results of no more than $0.2 \%$, suggesting the mesh is sufficiently fine. Eight-noded hexahedral brick elements were used to model the soil, the pile and the diaphragm wall, while two-noded truss elements were adopted to model the props. Roller and pin supports were applied to the vertical sides and the base of the mesh, respectively. Therefore, movements normal to the vertical boundaries and in all directions of the base were restrained. The water table was assumed to be at ground surface. Initially, the pore water pressure distribution was assumed to be hydrostatic. Free drainage was allowed at the top boundary of the mesh. The excavation process was simulated by deactivating soil elements inside excavation zone. In the meantime, the truss elements representing the props were activated.

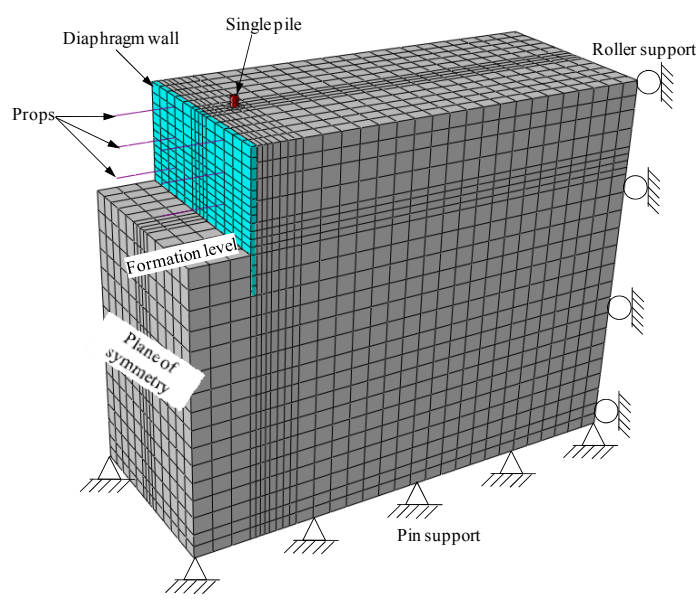

Fig. 2. Three dimensional finite element mesh and boundary conditions

\section{B. Constitutive Model and Model Parameters Used in Finite Element Analysis}

The basic hypoplastic model was developed to capture the non-linear behavior (upon monotonic loading at medium to large-strain levels) of granular materials [19-20]. The basic model consists of five parameters $\left(\mathrm{N}, \lambda^{*}, \kappa^{*}, \varphi_{\mathrm{c}}\right.$ and r) $\left(\mathrm{N}_{v} \lambda^{8}, \mathrm{~K}^{8}, \varphi_{\mathrm{a}}\right.$ and. Parameters $\mathrm{N}$ and $\lambda^{*}$ define the position and the slope of the isotropic normal compression line in the $\ln \left(1+\ln (1+\mathrm{e})\right.$ versus $\quad{ }^{\prime n} \operatorname{lnp}$ ' plane [21], e is the void ratio and p' is mean effective stress. The parameter $\kappa^{*} \quad$ defines the slope of the isotropic unloading line in the same plane. $\varphi_{c}$ is the critical state friction angle and the parameter $r$ controls the large strain shear modulus. To account for the strain-dependency and path-dependency of the soil stiffness (at small strains), authors in [22] further improved the basic hypoplastic model by incorporating the concept of intergranular strain. The intergranular strain concept requires five additional parameters $\left(\mathrm{R}, \beta_{\mathrm{r}}, \chi, \mathrm{m}_{\mathrm{T}}\right.$ and $\left.\mathrm{m}_{\mathrm{R}}\right)$ : $\mathrm{R}$ controlling the size of the elastic range, $\beta_{\mathrm{r}}$ and $\chi$ controlling the rate of stiffness degradation. The parameters $\mathrm{m}_{\mathrm{T}}$ and $\mathrm{m}_{\mathrm{R}}$ control the initial shear modulus upon $180^{\circ}$ and $90^{\circ}$ strain path reversal, respectively. In this hypothesised study, the parameters for silty clay were adopted the ones in [23]. All the model parameters for silty clay reported in [23] are summarised in Table I. The coefficient of lateral earth pressure at rest, $\mathrm{K}_{\mathrm{o}}$ is estimated in [24] by the following equation:

$$
K_{0}=\left(1-\sin \varphi^{\prime}\right)(O C R)^{\sin \varphi^{\prime}}
$$

TABLE I. MODEL PARAMETERS OF SILTY CLAY [23]

\begin{tabular}{|l|c|}
\hline \multicolumn{1}{|c|}{ Description } & Value \\
\hline Effective angle of shearing resistance at critical state: $\phi^{\prime}$ & $33^{\circ}$ \\
\hline $\begin{array}{l}\text { Parameter controlling the slope of the isotropic normal } \\
\text { compression line in the ln }(1+\mathrm{e}) \text { versus lnp plane, } \lambda^{*}\end{array}$ & 0.103 \\
\hline $\begin{array}{l}\text { Parameter controlling the slope of the isotropic normal } \\
\text { compression line in the ln }(1+\mathrm{e}) \text { versus lnp plane, } \kappa^{*}\end{array}$ & 0.015 \\
\hline $\begin{array}{l}\text { Parameter controlling the position of the isotropic normal } \\
\text { compression line in the ln }(1+\mathrm{e}) \text { versus lnp plane, } \mathrm{N}\end{array}$ & 1.31 \\
\hline $\begin{array}{l}\text { Parameter controlling the shear stiffness at medium- to } \\
\text { large- strain levels, } \mathrm{r}\end{array}$ & 0.3 \\
\hline $\begin{array}{l}\text { Parameter controlling initial shear modulus upon } 180^{\circ} \\
\text { strain path reversal, } \mathrm{m}_{\mathrm{R}}\end{array}$ & 12 \\
\hline $\begin{array}{l}\text { Parameter controlling initial shear modulus upon } 90^{\circ} \\
\text { strain path reversal, } \mathrm{m}_{\mathrm{T}}\end{array}$ & 12 \\
\hline Size of elastic range, $\mathrm{R}$ & $2 \times 10^{-5}$ \\
\hline $\begin{array}{l}\text { Parameter controlling the rate of degradation of the } \\
\text { stiffness with strain, } \beta \mathrm{r}\end{array}$ & 0.09 \\
\hline $\begin{array}{l}\text { Parameter controlling degradation rate of stiffness with } \\
\text { strain, } \chi\end{array}$ & 0.7 \\
\hline Initial void ratio, $\mathrm{e}$ & 1615 \\
\hline Dry density $\left(\mathrm{kN} / \mathrm{m}^{3}\right)$ & $1 \times 10^{-9}$ \\
\hline Coefficient of permeability, $\mathrm{k}(\mathrm{m} / \mathrm{s})$ & \\
\hline
\end{tabular}

The concrete pile, the diaphragm wall and the props were assumed to be linear elastic with Young's modulus of $35 \mathrm{GPa}$ and Poisson's ratio of 0.25 . The wall thickness was taken as $0.60 \mathrm{~m}$. The concrete unit weight was taken as $24 \mathrm{kN} / \mathrm{m}^{3}$. The parameters for the piles and the diaphragm wall are summarized in Table II.

TABLE II. CONCRETE PARAMETERS ADOPTED IN FINITE ELEMENT ANALYSIS

\begin{tabular}{|c|c|}
\hline Description & Value \\
\hline Young's Modulus, $\mathrm{E}$ & $35 \mathrm{GPa}$ \\
\hline Poisson's ratio, $v$ & 0.3 \\
\hline Density, $\rho$ & $2400 \mathrm{~kg} / \mathrm{m}^{3}$ \\
\hline
\end{tabular}

C. Numerical Modelling Procedure

Each numerical analysis is modeled according to the following steps:

Step 1: Set up the initial boundary and initial stress conditions (i.e., static stress conditions with varying $\mathrm{K}_{0}$ with depth). 
Step 2: Activate the brick elements representing single pile (modeled as "wished-in-place").

Step 3: Apply the working load (determined from numerical pile load test) on the pile.

Step 4: Allow excess pore pressure, which generated in result of the application of working load on the pile, to dissipate.

Step 5: Activate the brick elements representing the diaphragm wall.

Step 6: Staged multipropped excavation was simulated as described above. After excavating to $3 \mathrm{~m}$ depth, the first level of props was installed at $1 \mathrm{~m}$ below the ground surface. Soil was then excavated to $7 \mathrm{~m}$ below the ground surface, followed by installation of the second level of props at $4 \mathrm{~m}$ depth. Finally, excavation was extended to the target level of $10 \mathrm{~m}$ depth with installation of third level of props at $7 \mathrm{~m}$.

\section{INTERPRETATION OF COMPUTED RESULTS}

\section{A. Determination of Working Load for the Pile}

The objective of this parametric study was to investigate single pile load responses to an adjacent excavation. Prior to the simulation of the excavation, it was necessary to determine the ultimate axial load carrying capacity of the pile group. The working load can then be obtained using a factor of safety (FOS) of 3.0. Therefore, a numerical pile load test was carried out on a different finite element mesh to obtain the load settlement relationship and the capacity of the single pile without excavation. The load applied on the pile was gradually increased to $4 \mathrm{MN}$ over a period of $24 \mathrm{~h}$. The resulting pile load-displacement curve for the simulated pile is shown in Figure 3. The ultimate axial load capacity was determined based on a displacement-based failure criterion in [25]. This failure criterion is expressed as follows:

$$
\delta_{p h, \text { max }} \cong 0.045 d_{p}+\frac{1}{2} \frac{P_{h} L_{p}}{A_{p} E_{p}}
$$

where $\delta_{\mathrm{ph}, \max }$ is the maximum pile head movement which defines the ultimate load, $P_{h}$ is the pile head load, $L_{p}$ is the pile length, $E_{p}$ is the pile shaft elastic modulus, $A_{p}$ is the crosssectional area of the pile, and $d_{p}$ is the pile diameter. Based on the failure criterion, the ultimate bearing capacity of $3.22 \mathrm{MN}$ was calculated. With a factor of safety (FOS) of 3.0, the working load was determined to be $1.07 \mathrm{MN}$. Owing to the applied working load, the pile settled by $0.7 \% \mathrm{~d}_{\mathrm{p}}$ (Figure 3 ).

\section{B. Progressive Pile Settlement and Apparent Loss of the Pile Capacity During Excavation}

Figure 4 shows the incremental settlement $\left(\mathrm{S}_{\mathrm{p}}\right)$ of the pile with different excavation stages. Construction stages of the excavation are indicated by the depth $h$ the ground surface. $S_{p}$ and $h$ are normalized by the pile diameter $\left(d_{p}\right)$ and the final excavation depth $(\mathrm{He})$, respectively. The measured induced pile settlement due to excavation in centrifuge modeling reported in [9] is also shown for comparison. The centrifuge test was carried out to investigate the effects of a multipropped deep excavation (final depth of excavation $=8 \mathrm{~m}$ in prototype) inflight on the behavior of single pile (diameter of the pile $=1.25$ $\mathrm{m}$ in prototype) in dry Toyoura sand (i.e., $\mathrm{D}_{\mathrm{r}}=70 \%$ ). The embedded depth of the pile and clear distance between the pile and model wall is $20 \mathrm{~m}$ and $3 \mathrm{~m}$, respectively. A linear increase in $S_{p}$ of the pile was observed with the first two excavation stages $(\mathrm{h} / \mathrm{He}=0.7)$. However, the pile settled at increased rate due to subsequent excavation stage $(\mathrm{h} / \mathrm{He}=1.0)$. This may be attributed to two reasons. First, owing to reduction of shaft resistance due to excavation induced stress release, the pile had to settle substantially to further mobilize end-bearing (explained below). Second, the most part of the pile is placed within the boundaries of a major influence zone due to excavation-induced ground movement. Similar settlement characteristics of a single pile due to excavation observed from the centrifuge test reported in [9]. As expected, induced settlement of the single pile in medium dense sand was less than that of single pile in stiff clay. This is because the sand stiffness is higher than that of clay. The induced pile settlement due to excavation was $9.5 \mathrm{~mm}\left(1.2 \% \mathrm{~d}_{\mathrm{p}}\right)$.

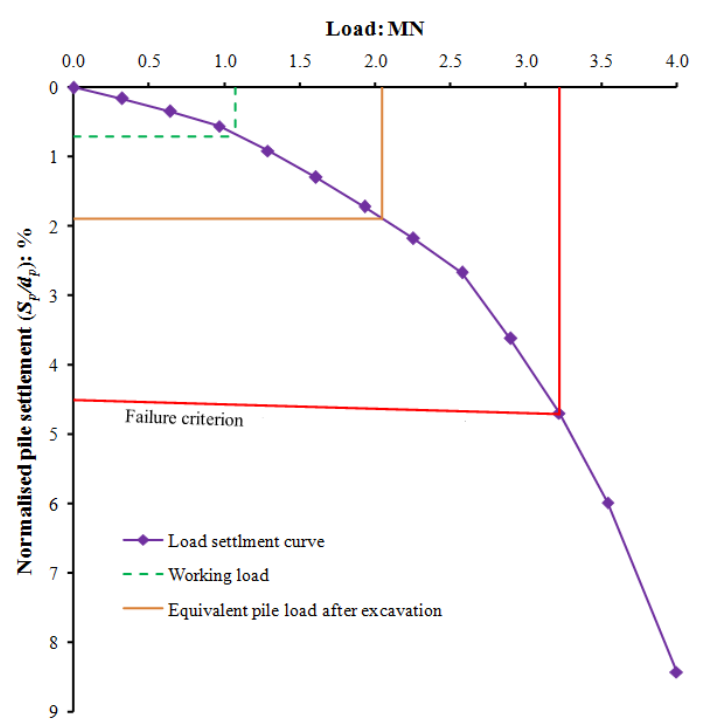

Fig. 3. Computed load settlement curve from the pile load test without excavation

Total pile settlement (including settlement due to working load and excavation) was $15.1 \mathrm{~mm}$ ( $1.9 \%$ pile diameter). This value satisfies a reliability-based serviceability criterion (56 $\mathrm{mm}$ ), which was developed based on 95 composite (reinforced concrete and steel) buildings subjected to settlement. This conclusion may not be applicable to scenarios in which the ground conditions or excavation depth are different from those adopted in this study. Considering pile capacity is often interpreted as using settlement criteria, and pile settlement due to excavation may be correlated with an apparent loss of pile capacity (ALPC). Therefore, the excavation induced settlement can be regarded as an additional load on the pile head. In this study, settlement of the pile due to the applied working load (before excavation) was about $0.7 \% \mathrm{~d}_{\mathrm{p}}(5.6 \mathrm{~mm})$ (see Figure 3 ). The excavation resulted in an additional pile settlement of $1.2 \%$ 
$\mathrm{d}_{\mathrm{p}}(9.5 \mathrm{~mm})$. With this additional settlement, the pile behaved as if it were loaded by an additional axial force of $1.0 \mathrm{MN}$ on the pile cap (based on load settlement curve shown in Figure 3 ). The additional load accounts for $31 \%$ of the ultimate pile capacity of the pile (based on the failure criterion presented in [26]). In other words, ALPC of $31 \%$ was due excavation. It should be noted that the reduction of pile capacity does not mean that the ultimate load capacity is physically reduced due to the excavation. It instead indicates the violation of the serviceability limit state of the pile as a result of the excavation-induced pile settlement and designers should take measures to control or mitigate this adverse effect.

\section{Computed Ground Deformation Mechanism and Deviatoric Strain}

Figure 5 shows computed incremental displacement vectors due to excavation. Computed incremental shear strain that the excavation induced stress released is also superimposed in the Figure. It can be observed that soil on the retained side moved towards the excavation, whereas the soil underneath the excavation heaved upwards due to vertical stress relief inside the exaction zone. Furthermore, it can be seen that excavationinduced ground movement is mainly bounded by a wedge at an angle of $45^{\circ}$ drawn from the wall toe. In addition to ground movement, significant shear strain (up to $1.44 \%$ ) is also developed extending nearly at $45^{\circ}$ from the wall toe. It can be seen that two-thirds of the pile shaft $\left(0 \leq \mathrm{Z} / \mathrm{L}_{\mathrm{p}} \leq 0.67\right)$ are located inside and pile toe is located outside the sliding wedge zone of ground movement. Because the two-thirds of the pile shaft are affected by the ground movement due to excavation induced stress release, shaft resistance decreased. To maintain equilibrium, the pile had to settle resulting in increment in endbearing. On the other hand, the pile toe is located within the region where shear strain is developed. As illustrated, the presence of the pile increases further the soil shear strain near the pile toe, as more end-bearing has to be mobilised to support vertical load transferred from the pile shaft to the pile toe after excavation.

\section{Changes in Axial Load Distribution}

Figure 6 illustrates the axial force distribution along the pile with normalised depth $\left(\mathrm{Z} / \mathrm{L}_{\mathrm{p}}\right)$ below the ground surface during excavation. The axial load distribution before excavation (after applying the working load) is also included in the figure as a reference. Before excavation, the pile carried approximately $70 \%$ of the working load $(1073 \mathrm{kN})$ with its shaft resistance and the remainder with its end-bearing resistance. It can be observed that excavation-induced reduction in normal stresses to the pile shaft and downward soil movement caused an increase in axial load along the entire length of the pile at different excavation stages. At the end of the first excavation stage, the maximum increment in the axial force $(14 \%$ of that at working load) was computed at $\mathrm{Z} / \mathrm{L}_{\mathrm{p}}=0.43$, which is above the formation level. By inspecting the axial load distribution after the first excavation stage, it is observed that along the upper portion of the pile $\left(Z / L_{p} \geq 0.2\right)$, the shaft resistance decreases to zero. Consequently, the load transferred to the lower portion of the pile. To maintain equilibrium, the pile had to settle (see Figure 5) to further mobilise the end-bearing and shaft resistance along the lower portion $\left(\mathrm{Z} / \mathrm{L}_{\mathrm{p}}>0.2\right)$. As the excavation reached at final depth, it caused a further reduction of the normal stresses to the pile shaft. Consequently, soil settled more than the pile resulting in negative skin friction (NSF) along the upper portion of the pile $\left(0 \leq \mathrm{Z} / \mathrm{L}_{\mathrm{p}} \leq 0.6\right)$. This suggests that this portion of the pile is subjected to "dragload" by the surrounding soil. This caused the pile to settle more than that due to pervious excavation stages (see Figure 6). To maintain vertical equilibrium of the pile, the soil surrounding the lower part of the pile $\left(\mathrm{Z} / \mathrm{L}_{\mathrm{p}}>0.6\right)$ resisted its settlement by mobilising positive skin friction (PSF) at the pile-soil interface and end-bearing resistance at the toe of the pile. Owing to end of the excavation, the end-bearing increased to $74 \%$.

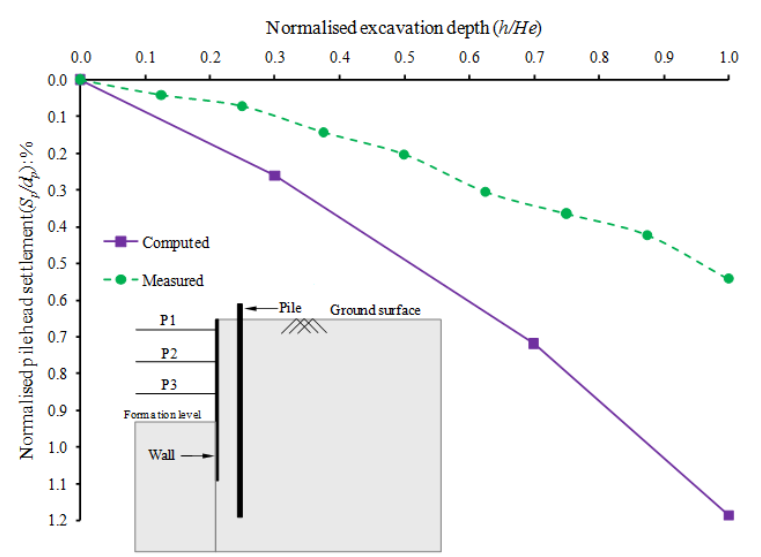

Fig. 4. Computed (this study) and measured ([9]) normalised pile head settlement during excavation

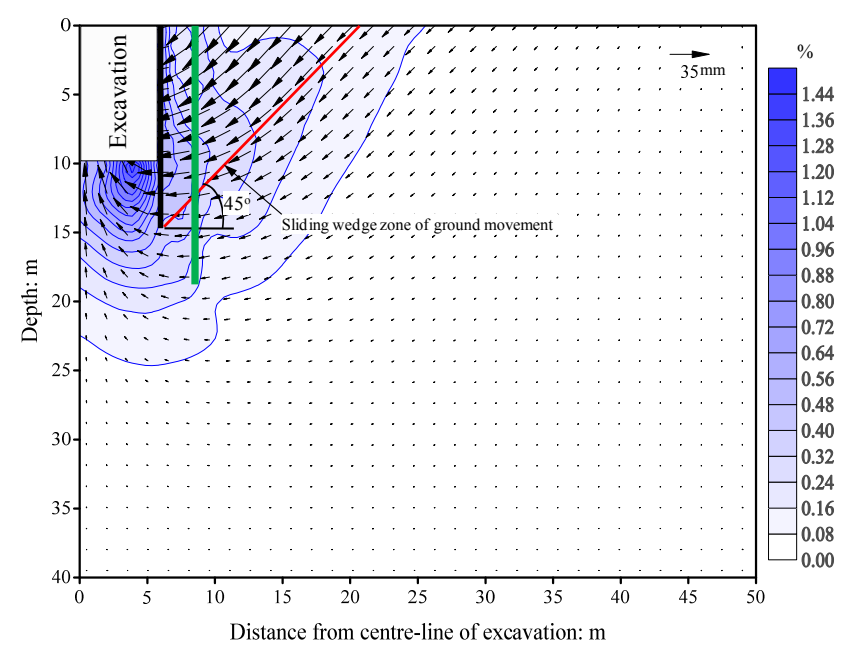

Fig. 5. Computed incremental ground movement and shear strain at the excavation end.

\section{E. Mobilised Shaft Resistance During Excavation}

To substantiate the previous discussion, the mobilized shaft resistance in the pile after the application of the working load (before the excavation) and the excavation is shown in Figure 7. In the figure, the depth below the ground surface $(Z)$ is 
normalized by the pile length $\left(\mathrm{L}_{\mathrm{p}}\right)$. The computed average mobilized unit shaft resistance $f(Z)$ at various depths was calculated based on the following equation:

$$
f(Z)=\frac{\Delta F_{(Z)}}{s \Delta Z}
$$

where $\Delta \mathrm{F}$ is the difference between the computed axial loads at two consecutive depths, $\Delta \mathrm{Z}$ is the vertical distance between the two consecutive depths, and $\mathrm{s}$ is the perimeter of the pile. As expected, after the application of the working load, the positive shaft resistance (soil supporting the pile) is mobilized along the entire length of the pile. The mobilized positive shaft resistance increased along pile depth with maximum shaft resistance of 31 $\mathrm{kPa}$ near the pile toe. It can be seen from the Figure that as excavation depth increases, mobilized shaft resistance decreased above the formation level $\left(\mathrm{Z} / \mathrm{L}_{\mathrm{p}}<0.5\right)$. On the completion of the excavation $(\mathrm{h} / \mathrm{He}=1.0)$, the mobilized shaft resistance at the upper portion of the pile $\left(\mathrm{Z} / \mathrm{L}_{\mathrm{p}}<0.5\right)$ decreased to negative and increased below formation level $\left(0.5<\mathrm{Z} / \mathrm{L}_{\mathrm{p}}<1.0\right)$. This caused negative skin friction (NSF) mobilization at the upper part of the pile shaft $\left(\mathrm{Z} / \mathrm{L}_{\mathrm{p}}<0.5\right)$ due to stress release and soil movement as mentioned above. This implies that this portion of the pile is "dragged" down by the surrounding soil, which settles due to excavation. To maintain vertical equilibrium of the pile, the soil surrounding the upper part of the pile resists from settling, by mobilizing PSF at the soil-pile interface. The neutral plane, where the zero shaft resistance is mobilized, is located at a depth of $\mathrm{Z} / \mathrm{L}_{\mathrm{p}}=0.45$ (above formation level). This location is consistent with the depth where the maximum axial load was induced. Consequently the load was transferred to the lower part of the pile. To support the applied working load and "dragload" resulting from NSF, the pile settled substantially to mobilize its end-bearing resistance.

Axial force: $\mathrm{kN}$

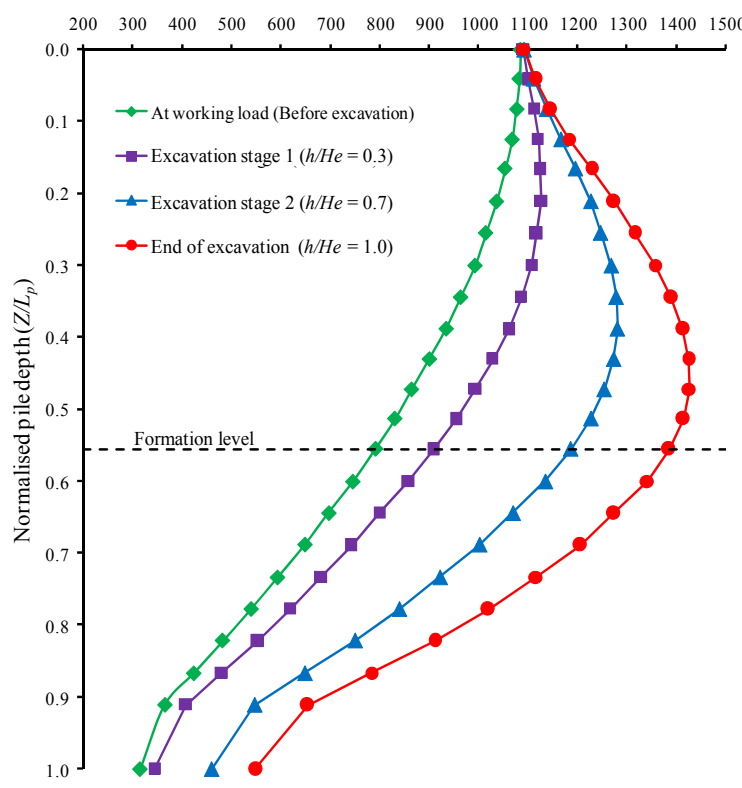

Fig. 6. Axial force with normalized depth

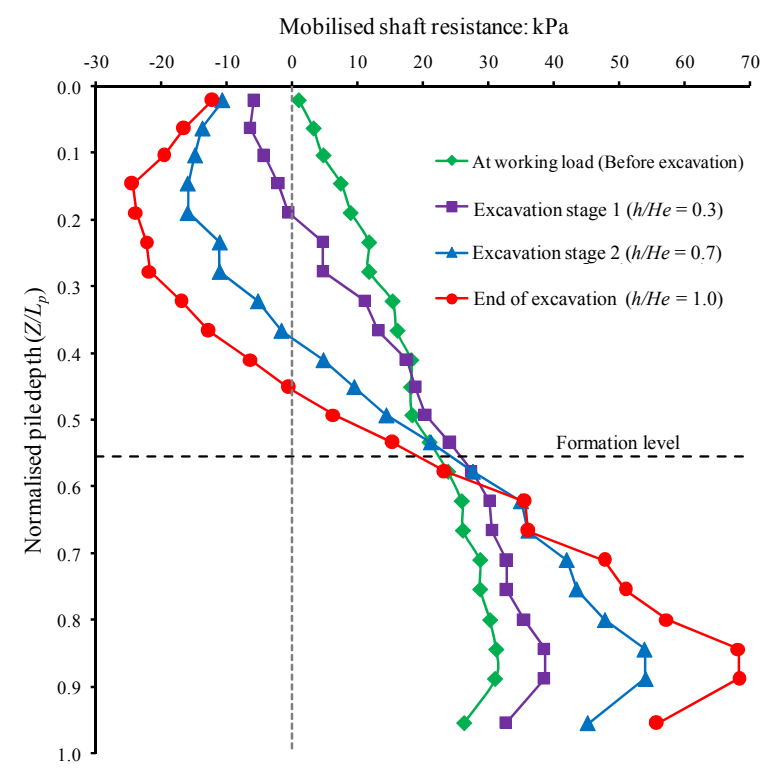

Fig. 7. Mobilized shaft resistance along the pile length at various stages of excavation

\section{F. Changes in Normal Stresses to the Pile Shaft During Excavation}

It is well recognized that the mobilized shaft resistance of a pile is related to the normal stresses to the pile shaft, interface friction angle between pile and soil and relative pile-soil displacement. To further elaborate the changes in mobilised shaft resistance along the pile length, normal stresses to the pile was extracted. Figure 8 shows changes in normal stresses to the pile shaft at different excavation stages. It can be observed that normal stresses to the pile shaft decreased with increment of excavation depth. The maximum reduction in normal stresses of $43 \mathrm{kPa}$ occurred at $\mathrm{Z} / \mathrm{L}_{\mathrm{p}}=0.5$ after completion of excavation $(\mathrm{h} / \mathrm{He}=1.0)$ and, as mentioned above, the shaft resistance decreased. As a result, to support the constant load applied on the pile head, the load borne by the shaft transferred to the pile toe. This led to increase stresses under the pile toe.

\section{G. Excavation-Induced Bending Moment and Lateral Deflection Along the Pile}

Figure 9 illustrates the induced bending moment along the pile with excavation. A positive bending moment means that tensile stress was induced along the pile shaft facing the exaction. Since there was no rigid constraint at the pile head, no bending moment was induced at/near the head of the pile at any stage of excavation. It can be observed that after first excavation stage $(\mathrm{h} / \mathrm{He}=0.3)$ negative bending moment induced along the pile length between $\mathrm{Z} / \mathrm{L}_{\mathrm{p}}=0.25$ and $\mathrm{Z} / \mathrm{L}_{\mathrm{p}}=0.95$. However, as excavation depth increases, positive bending moment induced in the pile. This is because the pile was subjected to lateral soil movement towards the excavation resulting from significant stress release (see Figure 8). The maximum positive bending moment $(350 \mathrm{kNm})$ was induced in the pile at $\mathrm{Z} / \mathrm{L}_{\mathrm{p}}=0.43$ near formation level. On the other hand negligible bending moment was induced near the pile toe. This was because the excavation-induced soil movement (see Figure 
5) and stress release (see Figure 8) near the pile toe was insignificant.

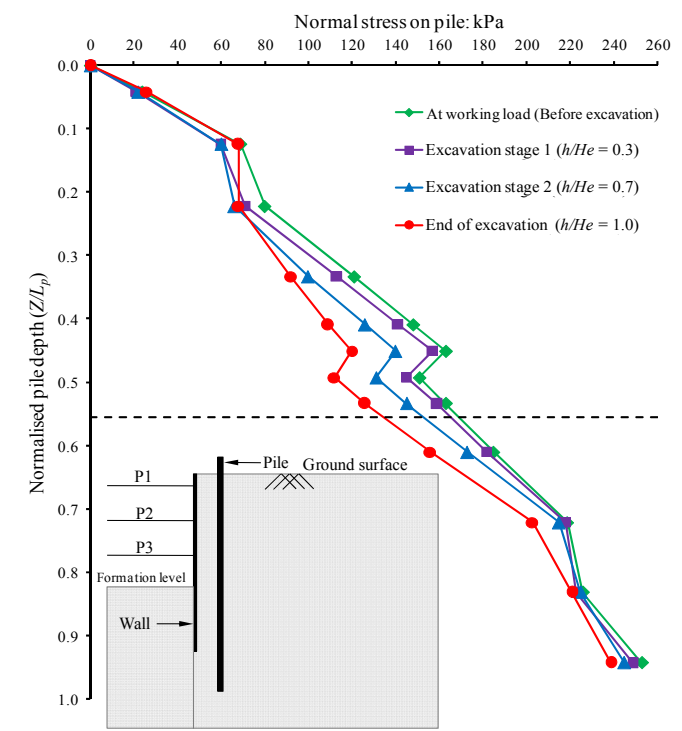

Fig. 8. Changes in normal stress acting on the pile during excavation

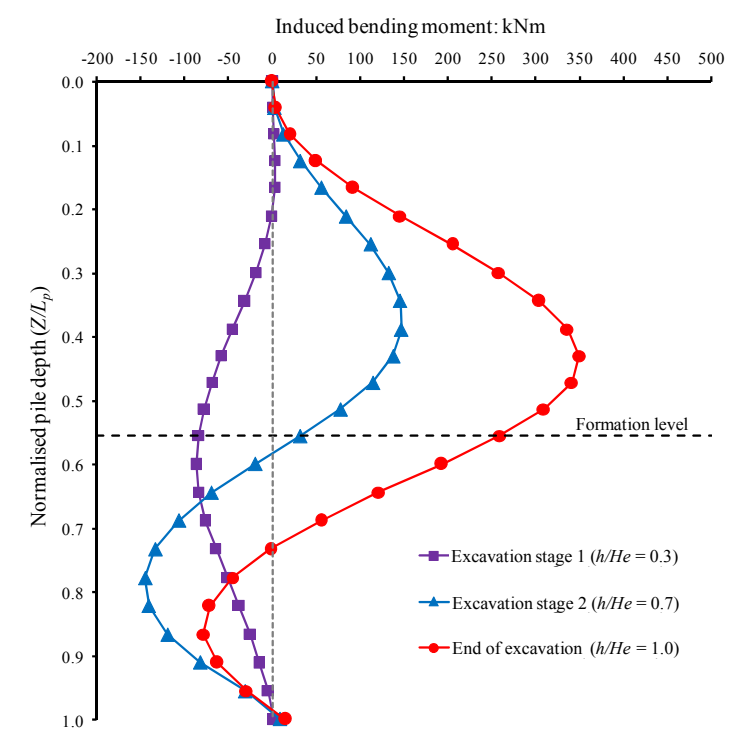

Fig. 9. Excavation-induced bending moment along the pile length

Figure 10 shows the computed pile lateral deflection during the excavation stages. Pile deflection toward the excavation is taken as the positive direction. Owing to horizontal stress release due to excavation and inward ground movement towards the excavation, the positive pile deflection occurred along the pile shaft. The magnitude of the pile deflection increased with excavation stages. Significant deflection of the pile occurred due to second $(\mathrm{h} / \mathrm{He}=0.7)$ and third $(\mathrm{h} / \mathrm{He}=1.0)$ excavation stages. The maximum deflection of about $29 \mathrm{~mm}$ was observed at $\mathrm{Z} / \mathrm{L}_{\mathrm{p}}=0.3$ after excavation. Since the pile head was not constrained, pile head deflected (with maximum deflection of $27 \mathrm{~mm}$ after completion of the excavation) towards the excavation. This is consistent with the result of excavation-induced bending moment (i.e. zero bending moment at the pile head).

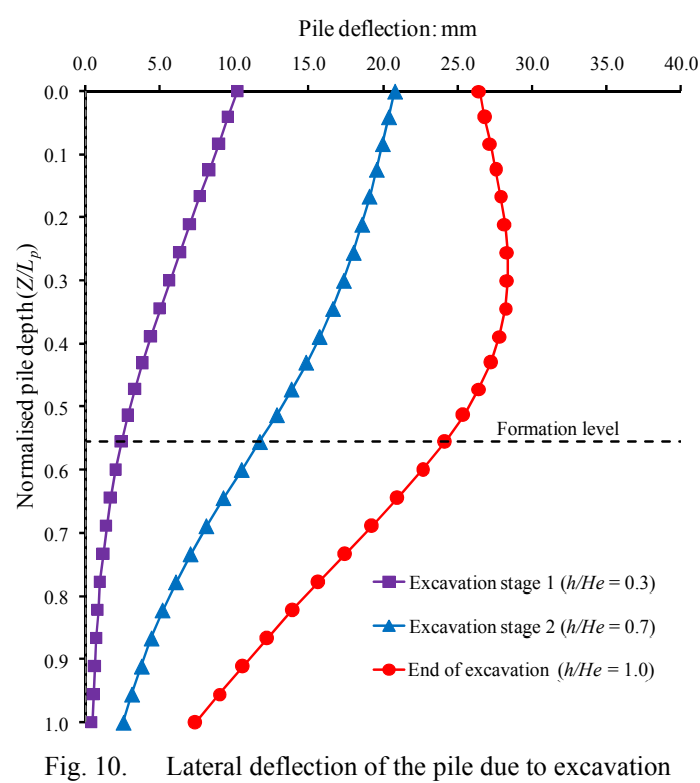

\section{SUMMARY AND CONCLUSIONS}

This study reports a 3D coupled consolidation numerical analysis investigating single pile responses to an adjacent excavation in saturated silty clay. Based on the ground conditions and geometry, the following conclusions can be drawn.

- Owing to the stiffness degradation of the clay surrounding the pile as a result of excavation-induced stress release and shear strain, the third excavation stage caused larger settlement than the first two stages. The final amount of induced settlement of the pile is $1.2 \%$ of the pile diameter. Based on the displacement-failure load criterion proposed in [26], the apparent loss of the capacity of the pile is $31 \%$.

- As far as load transfer mechanism along the pile is concerned, excavation-induced soil movement due to stress release mobilised negative shaft friction (NSF) at the upper part of the pile. Consequently, a downward load transfer is observed along the pile, further mobilising the pile endbearing.

- The normal stresses to the pile shaft decreased with increment of excavation depth. The maximum reduction in normal stresses of $43 \mathrm{kPa}$ occurred at $\mathrm{Z} / \mathrm{L}_{\mathrm{p}}=0.5$ (i.e. above formation level) after completion of excavation. Consequently, the shaft resistance decreased.

- The excavation induced the largest bending moment at $\mathrm{Z} / \mathrm{L}_{\mathrm{p}}=0.43$ near formation level. However, the maximum deflection of about $29 \mathrm{~mm}$ was observed at $Z / L_{p}=0.3$ (i.e. above formation level) after the completion of the excavation. 


\section{REFERENCES}

[1] R. J. Finno, S. A. Lawrence, N. F. Allawh, I. S. Harahap, "Analysis of performance of pile groups adjacent to deep excavation", Journal of Geotechnical and Geoenvironmental Engineering, Vol. 117, No. 6, pp. 934-955, 1991

[2] A. Goh, K. Wong, C. Teh, D. Wen, "Pile response adjacent to braced excavation", Journal of Geotechnical and Geoenvironmental Engineering, Vol. 129, No. 4, pp.383-386, 2003

[3] S. W. Jacobsz, J. R. Standing, R. J. Mair, T. Hahiwara, T. Suiyama, "Centrifuge modelling of tunnelling near driven piles", Soil and Foundations, Vol. 44, No.1, pp. 49-56, 2004

[4] S. Y. Lam, Ground movements due to excavation in clay:physical and analytical models, PhD Thesis, University of Cambridge, 2010

[5] D. Ong, C. F. Leung, Y. Chow, "Pile behavior due to excavationinduced soil movement in clay. I: Stable wall”, Journal of Geotechnical and Geoenvironmental Engineering, Vol. 132, No. 1, pp. 36-44, 2006

[6] D. Ong, C. F. Leung, Y. Chow, "Behavior of pile groups subject to excavation-induced soil movement in very soft clay", Journal of Geotechnical and Geoenvironmental Engineering, Vol. 135, No. 10, pp. 1462-1474, 2009

[7] C. Leung, Y. Chow, R. Shen. "Behavior of pile subject to excavationinduced soil movement", Journal of Geotechnical and Geoenvironmental Engineering, Vol. 11, No. 126, pp. 947-954, 2000

[8] C. Leung, J. Lim, R. Shen, Y. Chow, "Behavior of pile groups subject to excavation-induced soil movement", Journal of Geotechnical and Geoenvironmental Engineering, Vol. 135, No. 10, pp. 58-65, 2003

[9] C. W. W. Ng, J. Wei, H. G. Poulos, H. Liu, "Effects of Multipropped Excavation on an Adjacent Floating Pile". Journal of Geotechnical and Geoenvironmental Engineering, Vol. 143, No. 7, pp. 04017021, 2017

[10] H. G. Poulos, L. Chen, "Pile response due to excavation induced lateral soil movement", Journal of Geotechnical and Geoenvironmental Engineering, Vol. 123, No. 2, pp. 94-99, 1997

[11] D. S. Liyanapathirana, R. Nishanthan, "Influence of deep excavation induced ground movements on adjacent piles", Tunnelling and Underground Space Technology, Vol. 52, pp. 168-181, 2016

[12] M. Korff, R. J. Mair, F. A. Van Tol, "Pile-Soil Interaction and Settlement Effects Induced by Deep Excavations", Journal of Geotechnical and Geoenvironmental Engineering, Vol. 142, No. 8, pp. 040160342016, 2016
[13] J. H. Atkinson, D. Richardson, S. E. Stallebrass, "Effect of recent stress history on the stiffness of overconsolidated soil", Geotechnique, Vol. 40 No. 4, pp. 531-540, 1990

[14] J. H. Atkinson, G. Sallfors, "Experimental determination of stress-straintime characteristics in laboratory and in-situ tests", $10^{\text {th }}$ European Conference on Soil Mechanics and Foundation Engineering, Vol. 3, pp. 915-956, 1991

[15] B. C. B. Hsiung, "A case study on the behaviour of a deep excavation in sand", Computer and Geotechnics, Vol. 36, No. 4, pp. 665-675, 2009

[16] C. W. W. Ng, Y. Hong, G. Liu, T. Liu, "Ground deformations and soilstructure interaction of a multi-propped excavation in Shanghai soft clays", Geotechnique, Vol. 62, No. 10, pp. 907-921, 2012

[17] N. Loganathan, H. G. Poulos, D. P. Stewart, "Centrifuge model testing of tunnelling-induced ground and pile deformations", Geotechnique, Vol. 50, No. 3, pp. 283-294, 2000

[18] A. M. Marshall, R. J. Mair, "Tunneling beneath driven or jacked endbearing piles in sand", Canadian Geotechnical Journal, Vol. 48, No.12, pp. 1757-1771, 2011

[19] D. Masín, "A hypoplastic constitutive model for clays", International Journal for Numerical and Analytical Methods in Geomechanics, Vol. 29, No. 4, pp. 311-336, 2005

[20] D. Masín, I. Herle, "State boundary surface of a hypoplastic model for clays", Computers and Geotechnics, Vol. 32, No. 6, pp. 400-410, 2005

[21] R. Butterfield, "A natural compression law for soils", Geotechnique, Vol. 29, No. 4, pp. 469-480, 1979

[22] A. Niemunis, I. Herle, "Hypoplastic model for cohesionless soils with elastic strain range", Mechanics of Cohesive-frictional Materials, Vol. 2, No. 4, pp. 279-299, 1997

[23] D. Masín, J. Bohac, P. Tuma, "Modelling of a deep excavation in a silty clay", 15th European Conference on Soil Mechanics and Geotechnical Engineering, Vol. 3, pp. 1509-1514, 2011

[24] P. Mayne, F. Kulhawy, " $\mathrm{K}_{0}-\mathrm{OCR}$ relationships in soils", Journal of Geotechnical Engineering, Vol. 108, No. 6, pp. 851-872, 1982

[25] C. W. W. Ng, T. L. Y. Yau, J. H. M. Li, W. H. Tang, "New failure load criterion for large diameter bored piles in weathered geomaterials", Journal of Geotechnical and Geoenvironmental Engineering, Vol. 127, No. 6, pp. 488-498, 2001

[26] L. M. Zhang, A. M. Y. Ng, "Probabilistic limiting tolerable displacements for serviceability limit state design of foundations", Geotechnique, Vol. 55, No. 2, pp. 151-161, 2005 